the field experiment for Ss who acknowledged having seen the words. For purposes of comparison, the findings from a previous laboratory experiment are included (Zajonc, 1968). Of main importance is the frequency effect. For Ss claiming to have seen the words $(N=292)$, a simple effects test shows frequency to be a significant factor at the .001 level $(F=15.67)$. Of interest also is the overall main effect contrasting Ss claiming to have encountered the stimuli and those claiming not to have seen them. On the average, the former rated the critical words at 3.35 , while the latter rated them at 3.06 , a difference reliable at the .001 level $(F=35.75)$. For the filler words, which had not been displayed in the newspapers, no such difference was obtained. Additionally, the Ss tested in class did not differ from those polled by mail when the critical words were compared, and there was no interaction between the form of test administration and the frequency of appearance of the critical words. ${ }^{3}$

The above results can be taken as a further confirmation of the effects of mere exposure. It is of interest to note that the results of the field and laboratory experiments are quite similar, both demonstrating a fairly consistent logarithmic relationship between frequency of exposure and affective ratings.

\section{REFERENCES}

HARRISON, A. A. Response competition, frequency, exploratory behavior, and liking. Journal of Personality \& Social Psychology, $1968,9,363-368$

JOHNSON, R. C., THOMSON, C. W., FRINKE, $G$. Word values, word frequency, and visual duration thresholds. Psychological Review, $1960,53,332-342$.

MATLIN, M. A. W. Response competition as a mediating factor in the frequency-affect relationship. Unpublished doctoral dissertation, University of Michigan, 1969.

ZAJONC, R. B. Attitudinal effects of mere exposure. Journal of Personality \& Social Psychology, 1968, 9(Part 2), 1-27.

ZAJONC, R. B. Attraction, affiliation, and attachment. Paper presented at the Symposium on Comparative Social Behavior, Smithsonian Institute, May 1969.

\section{NOTES}

1. This reseatch was supported by NIMH Grant No. MH 12174-04.

2. The authors wish to express thanks to Miss Carol Budrou of The Michigan State News and to Mr. Randy Rissman of The Michigan Daily for their cooperation and assistance.

3. The second author's name and address were also printed on the questionnaires in the event that respondents, especially those reached by mail, desired further information about the study. It is of incidental interest and of some importance that some of the respondents could not resist also rating this author's name which, like the experimental stimuli, is a seven-letter three-syllable word. These ratings were consistently lower than those of the critical words-a further confirmation of the exposure effect since, to the best of our present krowledge, the name was first seen by our Ss when they responded to the questionnaire. It must also be disclosed, not without some chagrin, that the rating the name received was even lower than those assigned to the filler words. In the cause of fairness, the first author's name will be given equal status as nonsense stimulus word in future research.

\title{
Classical reaction time and signal rate in a vigilance setting
}

\author{
HANS-OLOF LISPER, University of \\ Uppsala, Uppsala, Sweden
}

Four Ss were employed in an experiment to determine if "classical" reaction time would increase over time in an ordinary vigilance setting. Two signal rates were used, one very high and the other low. The result was an increase in reaction time for the high rate and a constant reaction-time level for the low rate. This result was considered to support on inhibition theory of vigilance decrement, an explanation rejected on empirical evidence in vigilance research. The discrepancy between this and ordinary vigilance experiments was considered to be caused by differences in signal strength and as a consequence of the attention demanded.

It has been documented that the level of detection and/or response latency deteriorates as a function of the time of sustained observation (e.g., Buckner \& McGrath, 1963; Frankmann \& Adams, 1962). Signal characteristics in these so-called vigilance experiments have, more or less by definition, been changes in the stimulus situation (signals) which are not reported to $100 \%$. What happens when the signals are made very clear and, accordingly, are reported to $100 \%$ over the entire period of observation? In other words, what will happen to "classical" reaction time (RT) as a function of observation duration?

In experiments on fatigue and driving
(Lisper, 1966; Lisper et al, 1968), in which RT to a 90-dB auditory signal was used to estimate changes in the driver's spare capacity, it was found that RT increased as a function of driving time. These results would predict that "classical" RT would increase even in a laboratory vigilance setting.

In order to test this proposition, a pilot study with two signal rates was performed. Predictions from vigilance research (e.g., Baker, 1963) would suggest that a high signal rate would result in a shorter $\mathrm{RT}$ than a low rate. The pilot study did not confirm this hypothesis, but pointed at a far more interesting tendency, viz, the high signal rate gave a faster RT increase than the low rate over the $3 \mathrm{~h}$. This tendency, being reliable, might in fact revive N. H. Mackworth's (1950) inhibition theory as an explanation of the performance decrement in vigilance research. The experiment reported is thus specifically aimed at investigating this tendency, and the hypothesis is that a high signal rate gives a faster RT increase over time than does a low rate.

\section{METHOD}

Two female and two male students from an introductory psychology class served as Ss. All participated in two experimental sessions of $3 \mathrm{~h}$ each, separated by 1 week. The $S$ 's task was to depress a microswitch as fast as possible each time a 1,000-cps/90-dB signal was heard in the headphones. Reaction time was recorded by a Phillips decade counter and automatically recorded 


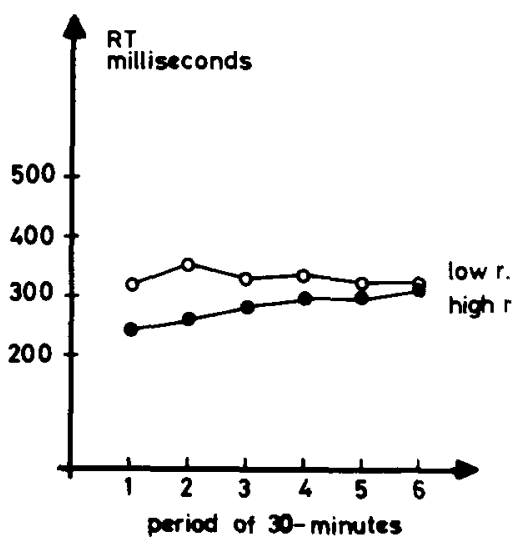

Fig. 1. Mean reaction time as a function of signal rate and time on the task.

by a Kienzle printer, Type DI. In Condition 1 , high stimulus rate, the average interstimulus interval was $15 \mathrm{sec}$, with a standard deviation of $5 \mathrm{sec}$. In this condition, the stimulus distribution was automatic. In Condition 2, low signal rate, the average interstimulus in terval was $5 \mathrm{~min}$, and the standard deviation was $2 \mathrm{~min}$ and $20 \mathrm{sec}$. In this condition, the stimulus distribution was handled by the $\mathrm{E}$. The two conditions were administered to the $S s$ in two different orders; one male and one female had the order $1-2$, and the other two Ss had the conditions in the opposite order. To minimize disturbances from the surrounding localities, the experiment was started at 7 p.m. Sounds from traffic and an adjacent church clock could not be avoided. The Ss were to surrender their watches but could, to some degree, tell the time by the church clock. In order to diminish learning effects, both sessions started with a training period of $10 \mathrm{~min}$ on the high signal rate.

RESULTS AND DISCUSSION

The time was divided into six blocks of 30 min for which the arithmetic means were calculated. In Table 1 and in Fig. 1, two things can be seen. First, the high signal rate gave a lower RT level than the low rate, as results from vigilance research would predict. Second, the RT increase over time (slope) was greater for the high signal rate, as the experimental hypothesis predicted. In fact, there was no increase in RT on low rate regarding the group averages. From Table 1, it can be seen that the difference between the signal rates were pervading over the $\mathrm{Ss}$, and that the lack of RT increase was valid for three of the four Ss.

This difference in slope between a high and a low signal rate is not completely in line with the usual observations in vigilance experiments. According to reviews (Bergum \& Klein, 1961; Frankmann \& Adams, 1963; J. F. Mackworth, 1968), performance is reduced or, in some cases, not affected at all by a decrease in stimulus rate. This

Table 1

Arithmetic Means in Milliseconds and Slope Values as a Function of Signal Rate and Time on the Task

\begin{tabular}{cllllllll}
\hline \multirow{2}{*}{ Subject } & & \multicolumn{7}{c}{ Period of 30-Min Number } \\
\cline { 3 - 8 } & Condition & 1 & 2 & 3 & 4 & 5 & 6 & Slope \\
\hline \multirow{2}{*}{1} & High rate & 221 & 228 & 233 & 252 & 258 & 276 & 10.97 \\
& Low rate & 248 & 334 & 282 & 302 & 281 & 338 & 8.89 \\
2 & High rate & 244 & 241 & 261 & 247 & 269 & 283 & 7.57 \\
& Low rate & 358 & 331 & 321 & 309 & 276 & 278 & -16.49 \\
3 & High rate & 219 & 247 & 254 & 274 & 289 & 305 & 16.46 \\
& Low rate & 290 & 362 & 347 & 344 & 332 & 287 & -3.09 \\
\multirow{2}{*}{4} & High rate & 266 & 308 & 359 & 390 & 360 & 370 & 20.20 \\
& Low rate & 348 & 368 & 342 & 365 & 377 & 358 & -2.86 \\
& High rate & 238 & 256 & 277 & 291 & 294 & 309 & 13.80 \\
& Low rate & 311 & 349 & 323 & 330 & 317 & 315 & -1.97 \\
\hline
\end{tabular}

reduction, although not explicitly stated, seems to be one of absolute level and not one of difference in slope. This impression is confirmed by a closer analysis of reports from experiments (Eason et al, 1965; Pope, 1962; Smith et al, 1966; Taub \& Osborme, 1968; Wiener, 1963) with different signal rates. In these, the difference between the stimulus rates was one of level, and any differences between slopes seemed more or less random.

On the basis of the disparity in level between low and high signal rates, N.H. Mackworth's (1950) inhibition theory was rejected. But difference in level can be explained in accordance with RT results by Bevan et al (1965) in which progressive effects were controlled. Consequently, in my opinion, the inhibition theory might have been rejected on the wrong premises and, in any case, a more correct way of testing it would be by predicting differences in slope. The theory would predict a faster deterioration of performance on high rates, a prediction which is verified by the present experiment.

Even if an inhibition explanation of the reported experiment might be reasonable, the above analysis of experiments on stimulus rate shows that it is not so well applicable in vigilance research. A possible reason for this differential action of stimulus rate might be in the differences in stimulus strength, as this is the only distinguishing factor between the reported vigilance experiments.

Different signal strengths cause differences in the attention demanded. If the signals are strong, the Ss do not have to pay attention to the signal source in order to detect the signals. On the other hand, if the signals are weak, as in vigilance experiments, the Ss have to pay close attention to the signal source in order to detect any signals. Besides, in this case, the signals as such are of comparatively little importance compared to the nonsignal output in determining the rate of decrement. This would explain why, in a specific vigilance experiment, there seems to be the same rate of deterioration, irrespective of the signal rate.
In the experiment reported, the signals are strong, and consequently, a low degree of attention is required. Under these circumstances, signal rate is important in itself, and the predictions will be in line with an inhibition theory.

\section{REFERENCES}

BAKER, C. H. Further toward a theory of vigilance. In D. N. Buckner and J. J. McGrath (Eds.), Vigilance: $A$ symposium. New York: McGraw-Hill, 1963.

BERGUM, B. O., \& KLEIN, I. C. A survey and analysis of vigilance research. HumRRO Research Report No. 8, November 1961.

BEVAN, W., HARDESTY, D. L., \& AVANT, L. L. Response latency with constant and variable schedules. Perceptual \& Motor Skills, 1965, 20 969-972.

BUCKNER, D. N., \& McGRATH, J. J. Vigilance: $A$ symposium. New York: McGraw-Hill, 1963.

EASON, R.G., BEARDSHALL, A., \& JAFFEE, S. Perfomance and physiological indicants of activation in a vigilance situation. Perceptual \& Motor Skills, 1965, 20, 3-13.

FRANKMANN, J. P., \& ADAMS, J. A. Theories of vigilance. Psychological Bulletin, 1962, 59, 257-272.

LISPER, H. O. Trötthet hos bilförare. En prövning av reaktionstid som prestationsmått. Unpublished fillic. thesis, University of Uppsala, 1966.

LISPER, H. O., DUREMAN, I., ERICSSON, S., \& KARLSSON, N. G. Effects of prolonged driving upon a subsidiary serial reaction time. 52nd Report, Psychology Department, University of Uppsala, 1968.

MACKWORTH, J. F. Vigilance, arousal, and habituation. Psychological Review, 1968, 75, 308-322.

MACKWORTH, N. H. Researches on the measurement of human performance. Medical Research Council Special Report Series, 1950 No. 268.

POPE, L. T. Attention level and visual and auditory monitoring. AMRL Technical Report 62-97, Aerospace Medical Research Laboratory, Wright-Patterson Air Force Base, Ohio, 1962.

SMITH, R. P., WARM, J. S., \& ALLUISI, E. A. Effects of temporal uncertainty on watchkeeping performance. Perception \& Psychophysics, 1966, 1, 293-299.

TAUB, H. A., \& OSBORNE, F. H. Effects of signal rate and stimulus rates on vigilance performance. Journal of Applied Psychology, 1968, 52, 133-138.

WIENER, E. L. Knowledge of results and signal rate in monitoring: A transfer of training approach. Journal of Applied Psychology, 1963, 47, 214-222. 